Springer Link

- Published: 19 November 2020

\title{
Impact Resistance and Strength Development of Fly Ash Based Self- compacting Concrete
}

- Selvaraj Kumar,

- Palanisamy Murthi,

- Paul Awoyera,

- Ravindran Gobinath \&

- Sathis kumar

$\underline{\text { Silicon (2020) Cite this article }}$

- 25 Accesses

- Metricsdetails

\section{Abstract}

The development of self-compacting concrete using alternative materials is expanding in recent years due to the technical and economic benefits of the mixture. This study focuses on the structural and compositional behavior of sodium hydroxide $(\mathrm{NaOH})$-activated fly ash based self-compacting concrete (SCC). Fly ash was partially replaced with Ordinary Portland Cement from 0$30 \%$. The tests performed on concrete samples include workability, strength, microstructural, and impact resistance. The results showed that activated fly ash reduces the heat of the hydration process of the concrete mixture but enhances pozzolanic reactions, which led to increased strength properties. The addition of activated fly ash modifies the mineralogy of the concrete, as evident in strength characteristics. The best performance of the activated fly ash based SCC, in terms of strength, was found at 10-15\% substitutions, which can somewhat reduce the cost of production of SCC and strength improvement advantage. 
This is a preview of subscription content, log in to check access.

Access options

Buy single article

Instant access to the full article PDF.

$$
34,95 €
$$

Tax calculation will be finalised during checkout.

$$
\text { Buy article PDF }
$$

Subscribe to journal

Immediate online access to all issues from 2019. Subscription will auto renew annually.

$$
73,83 €
$$

Tax calculation will be finalised during checkout.

Buy joumal subscription

\section{Rent this article via DeepDyve.}

Learn more about Institutional subscriptions

\section{Data Availability}

Data used in this study will be made available upon request.

Affiliations

1. Research Scholar, Anna University, Chennai, India Selvaraj Kumar

2. S R Engineering College, Warangal, Telangana, India Palanisamy Murthi \& Ravindran Gobinath

3. Department of Civil Engineering, Covenant University, Ota, Nigeria Paul Awoyera

4. Jay Shriram Group of Institutions, Tirupur, Tamil Nadu, India Sathis kumar 
Contributions

All authors whose names appear on the submission made substantial contributions to the conception, design of the work, acquisition, analysis, interpretation of data and wrting/revision of the article.

Corresponding author

Correspondence to Paul Awoyera.

\section{Ethics declarations}

Conflict of Interest

The authors declare that there is no conflict of interest.

Consent to Participate

Not applicable.

Consent for Publication

Not applicable.

\section{Additional information}

Publisher's Note

Springer Nature remains neutral with regard to jurisdictional claims in published maps and institutional affiliations.

\section{Rights and permissions}

Reprints and Permissions

\section{About this article}

Cite this article

- DOlhttps://doi.org/10.1007/s12633-020-00842-2

Keywords 


\section{Switch Edition}

- $\underline{\text { Contact us }}$

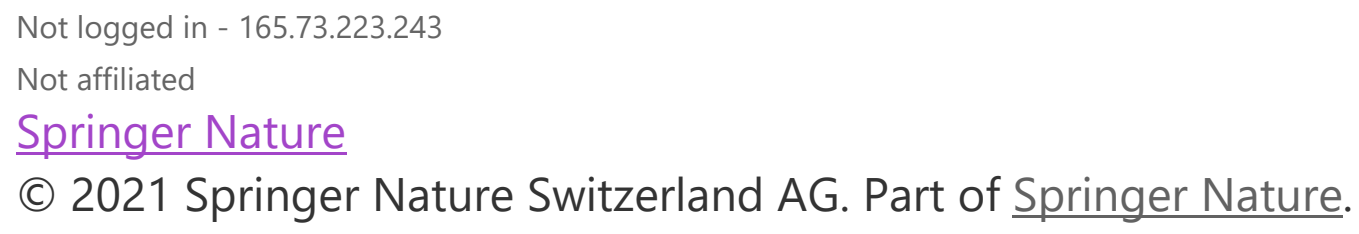

